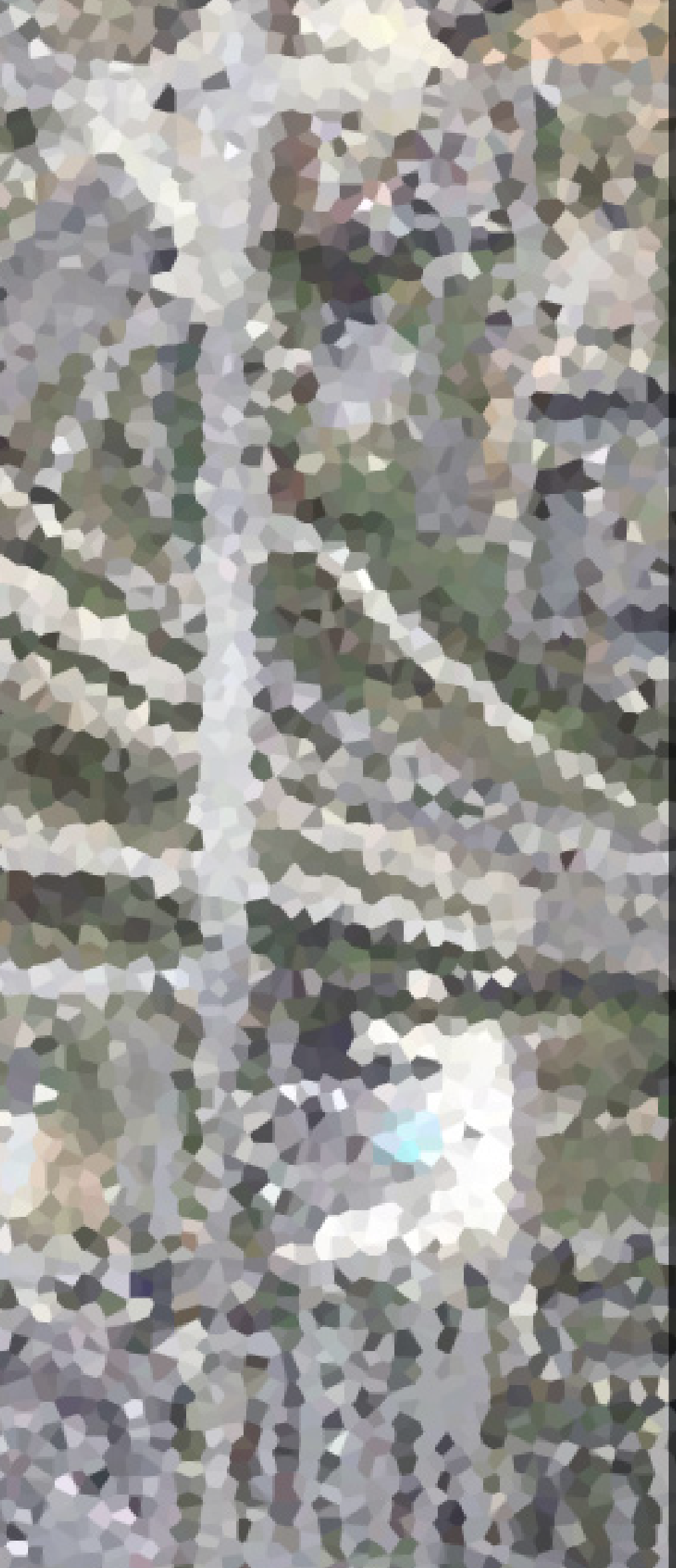

1. Arquiteta e Urbanista pelo Instituto Federal de Educação, Ciência e Tecnologia Fluminense, mestre em Cognição e Linguagem pela UENF, com MBA em Administração Pública e Gerência de Cidades pela UNINTER. E-mail: clayr_arruda@hotmail.com

2. Doutor em Literatura Comparada pela UFRJ. Professor Associado no Programa de Pós-graduação em Cognição e Linguagem.

E-mail: arruda.sergio@gmail.com

DOI: 10.5752/P.2316-1752.2016v23n33p104

(2)

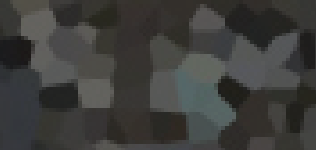




\title{
EVOLUÇÃO DISCURSIVA DO ETHOS NO PRÊMIO PRITZKER: ENTRE 2006 E 2016
}

\author{
ETHOS DISCOURSE EVOLUTION INTHE PRITZKER PRIZE: BETWEEN \\ 2006 AND 2016
}

LEVOLUCIÓN DISCURSIVA A TRAVÉS DEL ETHOS EN EL PREMIO PRIT-

ZKER: ENTRE 2006 Y 2016

\author{
Paola Clayr De Arruda Silveira ${ }^{1}$ \\ Sérgio Arruda De Moura²
}

\begin{abstract}
Resumo
A proposta deste artigo é apresentar a evolução do ethos, na perspectiva da Análise de Discurso de Linha Francesa, construído nos discursos de anunciação dos laureados pelo Prêmio Pritzker de Arquitetura, um dos prêmios mais importantes da categoria. Serão tratados trechos do discurso de apresentação do laureado, por Thomas Pritzker, presidente da Fundação Hyatt, retirados de revistas de âmbito nacional que divulgaram a escolha anualmente, no período compreendido entre os anos de 2006 a e 2016. Diante da construção de uma autodescrição do arquiteto laureado pelo enunciador do prêmio - aqui representado pela Fundação Hyatt - a análise bibliográfica servirá para a compreensão dos dados e informações que podem ser inferidas na esquematização dessa evolução discursiva, com possível aspecto influenciador sobre os demais arquitetos e profissionais da área.
\end{abstract}

Palavras-chave: Análise do Discurso. Ethos. Prêmio Pritzker.

\begin{abstract}
The proposal of this article is to present the evolution of the ethos, from the perspective of the French Line Discourse Analysis constructed in the discourses announcing the laureates by the Pritzker Prize of Architecture, one of the most important prizes of the category. Thomas Pritzker, president of the Hyatt Foundation, will give excerpts from the laureate's presentation speech from national magazines that publicized the choice annually, from 2006 to 2016. Before the construction of a self-description of the architect awarded by the award enunciator - here represented by the Hyatt Foundation - the bibliographic analysis will accompany the understanding of the data and information that can be inferred in the schematization of this discursive evolution, with possible influence on the other architects and professionals in the area.
\end{abstract}

Keywords: Discourse Analysis. Ethos. Pritzker Prize.

\begin{abstract}
Resumen
El propósito de este artículo es presentar la evolución de ethos, la perspectiva del análisis del discurso francés construido en el anuncio de los candidatos aptos discursos de Premio Pritzker de Arquitectura, uno de los premios más importantes de la categoría. Laureate extractos discurso de apertura estará a cargo de Thomas Pritzker, presidente de la Fundación Hyatt, tomadas de revistas nacionales que informaron la elección cada año, el periodo comprendido entre los años 2006 y 2016. En la construcción de un arquitecto auto-descripción ganador del anunciador premio - aquí representado por la Fundación Hyatt - una revisión de la literatura va a seguir para comprender los datos e información que pueden inferirse en la redacción de esta evolución discursiva con la posible factor de influencia de aspecto en los otros arquitectos y profesionales.
\end{abstract}

Palabras clave: Análisis del discurso. Ethos. Premio Pritzker.

Cadernos de Arquitetura e Urbanismo, v.23, n.33, $2^{0}$ sem. 2016 


\section{Introdução}

Criado em 1979, o Prêmio Pritzker, que indica laureados anualmente, é considerado o Prêmio Nobel da Arquitetura, pela sua relevância entre os estudiosos e profissionais envolvidos no processo arquitetônico. Sua importância está em servir como indicador dos pensamentos e decisões de inspiração e de projetação no campo da arquitetura e urbanismo, em nível internacional. A lista dos indicados ao Prêmio Pritzker é composta sempre por arquitetos das mais diversas nacionalidades e estilos, sendo seus trabalhos analisados por um júri técnico, formado por premiados em anos anteriores, críticos de arquitetura, dentre outros profissionais renomados no campo arquitetônico. A cada ano, ao apresentar o arquiteto ganhador do Prêmio, Thomas Pritzker, Presidente da Fundação Hyatt, faz um discurso, envolvendo as razões para a escolha do profissional e elogios ao premiado (PRITZKER, 2016).

O objetivo deste trabalho é verificar, por meio da análise desse discurso de divulgação do vencedor, a evolução do ethos no discurso de cada ano, no período de 2006 a 2016, por considerar essa premiação um instrumento de influência sobre um campo de atuação e pesquisa - a arquitetura.

Sob o arcabouço teórico da Análise do Discurso Francesa, o conceito de ethos se refere à criação de uma imagem de si por meio do discurso. Dessa maneira, ao afirmar que um enunciador pretende refletir uma autoimagem, significa também afirmar que o discurso traz consigo pistas do enunciador e do coenunciador, presentes aqui como os que interagem no processo discursivo. À criação dessa imagem de si no discurso, convencionou-se, por Maingueneau, chamar de ethos. Maingueneau (2005) afirma que não existe um ethos preestabelecido, mas, sim, construído no âmbito da atividade discursiva. Nessa perspectiva, a imagem de si é um fenômeno que se constrói na instância enunciativa e se mostra pelo seu discurso.

Em relação ao Prêmio Pritzker, essa autoimagem é referendada por um júri e não se trata da própria fundação ou do prêmio, e sim, da imagem descrita para terceiros, na figura dos arquitetos escolhidos, possuindo, por conseguinte, uma imagem para a arquitetura.

Neste trabalho serão apresentados trechos desses discursos anuais, divulgados por revistas com reportagens online, como a Revista AU, o Jornal Estadão, o G1.com, a Revista Casa, a Revista Casa Vogue, a ArchDaily e o Jornal O Globo, por estarem traduzidos para a Língua Portuguesa, sendo considerados suficientes para identificação do ethos - uma autoimagem da arquitetura, construída então pela Fundação e seu júri sobre fundamentos a serem debatidos mais adiante. 


\section{Prêmio Pritzker: aspectos do Ethos no no- bel da arquitetura e urbanismo}

O Prêmio Pritzker leva o nome da família Pritzker, sendo os fundadores, em 1979, o casal Jay e Cindy Pritzker, norte-americanos naturais e residentes em Chicago, e tem como objetivo inicial estimular não só uma maior consciência pública dos edifícios, mas também inspirar a criatividade na arquitetura. (PRITZKER, 2016).

O propósito do Pritzker, segundo o site da premiação, é:

honrar um arquiteto vivo ou arquitetos cujo trabalho construído demonstre uma combinação das qualidades de talento, visão e compromisso, que produziu contribuições consistentes e significativos para a humanidade e para o ambiente construído através da arte da arquitetura (PRITZKER, 2016).

Nesses aspectos, o prêmio é entregue anualmente pela Fundação Hyatt e seus premiados recebem uma doação US\$ 100.000,00 (cem mil dólares americanos), um certificado de citação formal e, a partir de 1987, um medalhão de bronze.

Acerca do processo de nomeação dos indicados, independe nacionalidade, raça, credo ou ideologia, com candidaturas de pessoas de diversas áreas dentro da arquitetura e Urbanismo que tenha conhecimento e interesse no avanço na área.

O diretor executivo solicita indicações de últimos premiados, arquitetos, acadêmicos, críticos, políticos e profissionais envolvidos em empreendimentos culturais, com experiência e interesse no campo da arquitetura. Além disso, qualquer arquiteto licenciado pode apresentar uma candidatura ao diretor executivo para apreciação pelo júri para o Prêmio Pritzker de Arquitetura, sendo divulgada a lista de indicados a cada mês de novembro, com o resultado da premiação no início do ano subsequente.

Quando o júri decide o premiado, o presidente da Fundação Hyatt, Thomas Pritzker, faz a leitura do discurso com as razões para a escolha do profissional, ressaltando aspectos de seus trabalhos e produção arquitetônica.

Em aspectos de aporte teórico, salienta-se que todo discurso pressupõe a construção de uma imagem daqueles que estão envolvidos no processo interativo, como aponta Fiorindo (2012):

(...) pois ao se projetar uma maneira de dizer não se pode ignorar as consequências desse ato, e tal atitude induz a uma construção de uma imagem que condiciona, em troca, a ação comunicativa; então os participantes dessa interação exercem poder um sobre os outros e é nesse jogo discursivo que eles mostram posições, ou melhor, papéis sociais que definem um caráter (FIORINDO, 2012, p. 1). 
o ethos se refere a textos orais e escritos, em que os enunciadores fornecem uma imagem de si através do discurso. Assim, dizer que os participantes do discurso criam uma imagem de si através dele, significa também afirmar que o discurso carrega as marcas do enunciador e do coenunciandor, entendidos como aqueles que interagem no processo discursivo (HEINE, 2007, p. 41).

Dessa maneira, as imagens do enunciador e do coenunciador atuam no campo discursivo, constituindo-se no processo enunciativo. A partir disso, verifica-se que o ethos não está no enunciado, mas na enunciação. Segundo Discini (2008), o ethos encontra-se no sujeito construído no discurso, é uma imagem do autor, não o autor real (de carne e osso), mas um autor discursivo (construído pela tessitura e pela textura do texto). Essa relação de ethos como estilo na enunciação marca o jeito individual do ser social.

O conceito de ethos é recuperado e ampliado pela Análise do Discurso a partir das discussões de Maingueneau (2008), na concepção discursiva do ethos como situações discursivas diversas que se estendem aos enunciados orais, escritos, na modalidade verbal, visual ou verbo-visual, representando uma pessoa ou até mesmo uma ou várias instituições. Maingueneau (2005) afirma que não existe um ethos preestabelecido, mas, sim, construído no âmbito da atividade discursiva. Nessa perspectiva, a imagem de si é um fenômeno que se constrói dentro da instância enunciativa e se mostra através de seu discurso.

Barthes (apud Maingueneau, 2005, p. 70) define a construção da imagem como "os traços de caráter que o orador deve mostrar ao auditório (pouco importando sua sinceridade) para causar boa impressão: são os ares que assume ao se apresentar [...]. O orador enuncia uma informação e ao mesmo tempo diz: eu sou isso e não aquilo".

Maingueneau (2008) indica características para reconhecer um discurso detentor de um ethos, sendo:

- o ethos é uma noção discursiva, ele se constrói através do discurso, não é uma "imagem" do locutor exterior a sua fala;

- o ethos é fundamentalmente um processo interativo de influência sobre o outro;

- é uma noção fundamentalmente híbrida (sociodiscursiva), um comportamento socialmente avaliado, que não pode ser apreendido fora de uma situação de comunicação precisa, integrada ela mesma numa determinada conjuntura socio-histórica (MAINGUENEAU, 2008, p. 17).

Na perspectiva de Amossy (2005), as pistas deixadas no discurso permitem a sugestão de imagens para o enunciador; no 
caso do Pritzker, sugestões da imagem do que quer a Fundação Hyatt e seu júri:

Para construir tal imagem, não é necessário que o enunciador fale sobre si ou apresente para os ouvintes suas características, suas qualidades e defeitos, pois, no momento do discurso, lançam-se pistas acerca desta imagem: seu estilo, sua visão de mundo, seu conhecimento acerca de determinados assuntos, dentre outros, que permitirão aos ouvintes realizarem a construção da imagem do enunciador (AMOSSY, 2005, p. 9)

Na Análise do Discurso Francesa, tendo como guia os estudos de Maingueneau, o diálogo sobre ethos vai além dos estudos elaborados pela Retórica, em Aristóteles, por se estender a todo e qualquer discurso, mesmo àqueles presentes no texto escrito/falado.

Heine (2008) apresenta essas exposições de Maingueneau, que afirma que o ethos se liga diretamente ao tom que engendra o discurso. Esse tom, por sua vez, estaria ligado a uma corporalidade e ao caráter do enunciador:

Assim, pode-se dizer que o ethos relaciona-se com a construção de uma corporalidade do enunciador por intermédio de um tom lançado por ele no âmbito discursivo. O tom permitirá ao leitor construir, no texto escrito, uma representação subjetiva do corpo do enunciador, corpo este manifestado não fisicamente, mas construído no âmbito da representação subjetiva. A imagem corporal do enunciador faz emergir a figura do fiador, entendida aqui como aquela que deriva da representação do corpo do enunciador efetivo, se construindo no âmbito do discurso. O fiador é aquele que se revela no discurso e não corresponde necessariamente ao enunciador efetivo. (HEINE, 2008, p. 158)

Essa "boa impressão', esse "poder de persuasão", são os objetos almejados pelo Prêmio Pritzer e essa hipótese será abordada nos tópicos seguintes.

\section{Apresentação dos laureados do prêmio Pritzker entre 2006 e 2016}

\section{6 - Paulo Mendes da Rocha}

O segundo arquiteto brasileiro a ser o ganhador do prêmio (Oscar Niemeyer recebeu o prêmio em 1988) foi escolhido pelo júri por ter "produzido edifícios com um profundo entendimento da poética do espaço, com a capacidade de modificar o terreno e o espaço com sua arquitetura, esforçando-se para atender às necessidades humanas, sociais e estéticas" 3 .
3. Revista AU online. Paulo Mendes da Rocha recebe Prêmio Pritzker. Edição 146 - Maio 2006. Disponível em: <http://au.pini.com.br/arquiteturaurbanismo/146/artigo22172-1.aspx>. Acesso em 13 jan. 2016.
Cadernos de Arquitetura e Urbanismo, v.23, n.33, 2" sem. 2016 
Em entrevista à Revista AU, Mendes da Rocha respondeu sobre o que significou o Pritzker: "O importante nessa premiação não é a pessoa, mas as questões intelectuais e do debate arquitetônico atual, que passam pelo reconhecimento de uma arquitetura latino-americana que luta pela defesa da natureza, do meio ambiente, pelo direito à cidade, pela qualidade do ensino e pela inclusão social, pela aproximação das pessoas".

\section{7 - Richard Rogers}

Arquiteto modernista, autor de projetos impactantes como a Torre 3 do World Trade Center, Nova York e do Centro Georges Pompidou, em Paris, foi anunciado por Thomas Pritzker como um "defensor da vida urbana e acredita no potencial da cidade como catalisadora de transformações sociais" 4 .

Ainda segundo o Estadão, o presidente do júri do Pritzker, Lorde Palumbo, descreveu Rogers como "não apenas mestre da grande construção urbana, mas também criador de sua espécie própria de expressionismo arquitetônico".

\section{8 - Jean Nouvel}

Atuante na área por quatro décadas, Nouvel, arquiteto contemporâneo, foi apresentado por Thomas Pritzker como "profissional de valente busca de novas ideias e questionamento das normas aceitas, para superar os limites em seu campo de atividade" ${ }^{\prime}$.

\section{9 - Peter Zumthor}

Thomas J. Pritzker citou as palavras do júri para o arquiteto suíço: "Peter Zumthor é um mestre, um arquiteto admirado por seus colegas em todo o mundo por seu trabalho focado, íntegro e excepcionalmente determinado. Todos os prédios têm uma presença forte e atemporal. Ele possui um raro talento para combinar um pensamento claro e rigoroso com uma dimensão poética, o que resulta em trabalhos que nunca terminam de nos inspirar" 6 .

Ao receber o prêmio, na cerimônia de premiação, Zumthor declarou: "Eu acho que a linguagem da arquitetura não depende de estilos específicos. Todo prédio é construído para um uso específico, num local específico e numa sociedade específica. Esse é o ponto de partida para a construção de meus prédios".

\section{0 - Ryue Nishizawa e Kazuyo Sejima (SANAA)}

Esta foi apenas a terceira vez que o Prêmio Pritzker foi dado a mais de uma pessoa em um único ano. A primeira foi em 1988, quando Oscar Niemeyer e Gordon Bunshaft foram premiados; a segunda foi para os sócios suíços Jacques Herzog e Pierre de Meuron. As obras dos arquitetos do escritório SANAA "valorizam o espaço contínuo, a leveza e a transparência e os colocam à frente de seu tempo"7.
4. Jornal Estadão online. Arquiteto britânico Richard Rogers ganha Prêmio Pritzker. Atual. 28 mar. 2007. Disponíve em: <http://cultura.estadao.com.br/ noticias/geral,arquiteto-britanico-richardrogers-ganha-premio-pritzker,20070 328p2016>. Acesso em 13 jan. 2016.

5. G1.com. Francês Jean Nouvel recebe o prêmio Pritzker de Arquitetura.

Atual. 30 mar. 2008. Disponível em: <http://g1.globo.com/Noticias/ PopArte/0,,MUL375102-7084,00FRANCES+JEAN +NOUVEL+RECEBE+ O+PREMIO+PRITZKER+DE+ARQUITET URA.html >. Acesso em 13 jan. 2016.

6. Revista Casa. Prêmio Pritzker 2009 vai para o arquiteto suiço Peter Zumthor. Atual. 09 abr. 2014. Disponível em: <http://casa.abril.com.br/materia/premiopritzker-2009-vai-para-o-arquiteto-suicopeter-zumthor>. Acesso em 13 jan. 2016.

7. Revista Casa. Arquitetos japoneses recebem o Pritzker 2010. Atual. 10 abr. 2014. Disponível em: <http://casa.abril. $\mathrm{com} . \mathrm{br} / \mathrm{materia/arquitetos-japoneses-}$ recebem-o-pritzker-2010>. Acesso em 13 jan. 2016 


\section{1 - Souto de Moura}

Souto de Moura é autor de projetos das mais variadas tipologias arquitetônicas e em 2011 foi admitido no olimpo da arquitetura, sendo o segundo português a receber a premiação - o primeiro foi Álvaro Siza, em 1992. Nas palavras dos jurados, "suas construções possuem uma capacidade única de transmitir características aparentemente conflitantes de poder e modéstia, alarde e sutileza, autoridade ousada e uma sensação de intimidade ao mesmo tempo"8.

O arquiteto é reconhecido pelo rigoroso manejo dos materiais, em especial de concreto, madeira, aço e, com destaque, da pedra, abundante na região.

\section{2 - Wang Shu}

Durante o anúncio da decisão do jurado, Thomaz Pritzker afirmou sobre Wang Shu:

O fato que um arquiteto chinês tenha sido selecionado pelo jurado representa um passo significante para perceber o papel que a China terá no desenvolvimento dos ideais arquitetônicos. Além disso, durante as últimas décadas, o sucesso da urbanização chinesa será importante tanto para o país como para o mundo. Essa urbanização como a urbanização em todo o mundo, precisa estar em harmonia com a cultura e as necessidades locais. As oportunidades sem precedentes para o planejamento e desenho urbano, possibilitadas pela China, irão querer estar em harmonia tanto com sua longa e única tradição do passado como com suas futuras necessidades para o desenvolvimento sustentável $\left.\right|^{9}$.

\section{3 - Toyo Ito}

Surgindo como sexto arquiteto japonês a receber a láurea - os cinco primeiros foram Kenzo Tange (1987), Fumihiko Maki (1993), Tadao Ando (1995) e o time do Sanaa (Kazuyo Sejima e Ryue Nishizawa, 2010).

O júri do Pritzker destacou a capacidade de Ito de "sintetizar muitas linguagens arquitetônicas e funcionalidades na expressão de uma "sintaxe" muito pessoal, inspirado nas estruturas orgânicas encontradas na natureza e na sensualidade do ser humano" 10 .

\section{4 - Shigeru Ban}

Outra vez um japonês recebe a premiação, Ban, conhecido mundialmente por trabalhar com técnicas de construção de casas para vítimas de desastres, como o terremoto que atingiu o Japão em 2011.
8. Revista Casa Vogue. Souto de Moura leva Pritzker 2011. Disponível em:

<http://revista.casavogue. globo.com / arquitetura/souto-de-moura-leva-premiopritzker-2011/>. Acesso em 16 jan.2016.

9. ArchDaily. Prêmio Pritzker 2012: Wang Shu. Atual. 27 fev. 2012. Disponível em: $<$ http://www.archdaily.com.br/br/0135138/premio-pritzker-2012-wang-shu>. Acesso em 13 jan. 2016.

10. ArchDaily. Prêmio Pritzker 2013: Toio Ito. Atual. 17 mar. 2013. Disponível em: $<$ http://www.archdaily.com.br/br/01103428/premio-pritzker-2013-toyo-ito>. Acesso em 13 jan. 2016. 
Segundo a decisão do júri, "através de excelentes projetos, em resposta a desafios emergenciais, Shigeru Ban ampliou o papel do oficio. Ele conquistou um espaço para arquitetos participarem do diálogo com os governos, órgãos públicos, filantropos e comunidades afetadas" 11 .

\section{5 - Frei Otto}

Otto é o segundo arquiteto alemão a receber a honraria, seguindo Gottfried Böhm, premiado em 1986, e o primeiro a recebê-la postumamente. A notícia foi antecipada em duas semanas devido ao recente falecimento do arquiteto e engenheiro estrutural.

Segundo o júri do Prêmio, Frei Otto:

tem produzido arquitetura sem precedentes criativos, criando conhecimento. Nisso reside sua profunda influência: não em como as formas podem ser copiadas, mas através dos caminhos que se abriram graças às suas pesquisas e descobertas. Suas contribuições no campo da arquitetura não são apenas inteligentes e talentosas, são também generosas. Por suas ideias visionárias, sua crença em compartilhar livremente conhecimento e invenções, seu espírito de colaboração e a preocupação com o uso cuidadoso dos recur$\operatorname{sos}^{12}$.

\section{6 - Alejandro Aravena}

Destacando sua capacidade de ampliar o campo de ação do arquiteto para alcançar soluções que permitam melhorar os contextos urbanos e fazer frente à crise mundial de habitação, o júri selecionou o arquiteto chileno Alejandro Aravena, "um arquiteto mais socialmente engajado [...]. Ele tem um profundo conhecimento tanto da arquitetura como da sociedade civil, algo que se reflete em seus escritos, seu ativismo e seus projetos. O papel do arquiteto está agora sendo desafiado a servir a necessidades sociais e humanitárias maiores"13.

A partir dessa demonstração dos premiados conforme os anos, foi possível elaborar uma esquematização para melhor visualizar esses acontecimentos, de modo a colaborar para a identificação do ethos formado no discurso da Fundação Hyatt para premiar um arquiteto e não outro, na hipótese de seguir um panorama discursivo mundial.

\section{Esquematização para resultados e dis- cussão}

A seguir, a esquematização indica, de modo mais visual, os resultados do Prêmio Pritzker no decorrer da década de 20062016. Numa estatística básica, $46 \%$ dos resultados referemse a arquitetos europeus, $36 \%$ arquitetos asiáticos e $18 \%$ arquitetos latinos.
11. O Globo. Shigeru Ban recebe o prêmio Pritzker 2014. Atual. 24 mar. 2014. Disponível em: <http://oglobo globo.com/cultura/shigeru-ban-recebepremio-pritzker-2014-11971574>. Acesso em 13 jan. 2016.

12. ArchDaily. Frei Otto, laureado póstumo do Prêmio Pritzker 2015. Atual. 10 mar. 2015. Disponível em: <http:// www.archdaily.com.br/br/763568/freiotto-premio-pritzker-2015>. Acesso em 13 jan. 2015.

13. ArchDaily. Alejandro Aravena vence o Prêmio Pritzker 2016. Disponível em: <http://www.archdaily.com. br/ br/780248/alejandro-aravena-vence-opremio-pritzker-2016>. Acesso em 13 jan. 2016 


\begin{tabular}{|c|c|c|c|}
\hline ANO & PAis & DISCURSO DO JURI & ETHOS \\
\hline 2006 & BRASIL & $\begin{array}{l}\text { "produziu edifícios com um profundo } \\
\text { entendimento da poética do espaço, com } \\
\text { a capscidade de modificar o terreno e o } \\
\text { espaço com sua arquitetura, esforçando- } \\
\text { se para atender às necessidades } \\
\text { humangs, socisis e estéticas". }\end{array}$ & $\begin{array}{l}\text { O espaço que serve } \\
\text { (social e ambiental). }\end{array}$ \\
\hline 2007 & REINO UNIDO & $\begin{array}{l}\text { "defensor da vida urbana e acredita no } \\
\text { potencial da cidade como catalisadors } \\
\text { de transformaçöes sociais". }\end{array}$ & $\begin{array}{l}\text { Cidade catalissdora } \\
\text { de transformação } \\
\text { social. }\end{array}$ \\
\hline 2008 & FRANÇA & $\begin{array}{l}\text { "profissional de valente busca de novas } \\
\text { ideias e questionamento das normas } \\
\text { aceitas, para superar os limites em seu } \\
\text { campo de atividade". }\end{array}$ & $\begin{array}{l}\text { Debate das normas. } \\
\text { contra os limites do } \\
\text { campo. }\end{array}$ \\
\hline 2009 & suiçA & $\begin{array}{l}\text { "Todos os prédios têm ums presença } \\
\text { forte e atemporsl. Ele possui um raro } \\
\text { talento para combinar um pensamento } \\
\text { claro e rigoroso com ums dimensão } \\
\text { poétics, o que results em trabalhos que } \\
\text { nunca terminam de nos inspirar". }\end{array}$ & $\begin{array}{l}\text { Inspiração forte e } \\
\text { atemporal. }\end{array}$ \\
\hline 2010 & JAPÃO & $\begin{array}{l}\text { As obras dos arquitetos do escritório } \\
\text { SANAA "valorizam o espaço continuo, a } \\
\text { leveza e a transparência e os colocam } \\
\text { a frente de seu tempo". }\end{array}$ & $\begin{array}{l}\text { Leveza e } \\
\text { transparència para o } \\
\text { espaço. }\end{array}$ \\
\hline 2011 & PORTUGAL & $\begin{array}{l}\text { "sugs construçöes possuem ums } \\
\text { capacidade únics de transmitir } \\
\text { características } \\
\text { conflitantes poder e modéstia, alarde e } \\
\text { sutilezs". }\end{array}$ & $\begin{array}{l}\text { Transmissão de } \\
\text { sutileza e glamour ao } \\
\text { espaço. }\end{array}$ \\
\hline 2012 & CHINA & $\begin{array}{l}\text { "representa um passo significante pars } \\
\text { perceber o papel que a China terá no } \\
\text { desenvolvimentor dos ideais } \\
\text { arquitetónicos. Além disso, durante as }\end{array}$ & $\begin{array}{l}\text { Influència da China } \\
\text { na arquitetura e } \\
\text { urbanismo mundial. }\end{array}$ \\
\hline & & $\begin{array}{l}\text { últimas décadas, o sucesso da } \\
\text { urbanização chinesa será importante } \\
\text { tanto para o pais como para o mundo". }\end{array}$ & \\
\hline 2013 & JAPÃO & $\begin{array}{l}\text { Capacidade de "sintetizar muitas } \\
\text { linguagens arquitetônicas (...). inspirado } \\
\text { nas estruturas orgànicas encontradss ng } \\
\text { naturezs e no sensuglidgde do ser } \\
\text { humano". }\end{array}$ & $\begin{array}{l}\text { Sintese das } \\
\text { linguagens } \\
\text { arquitetönicas. }\end{array}$ \\
\hline 2014 & JAPÃO & $\begin{array}{l}\text { "Ele conquistou um espaço para } \\
\text { arquitetos participarem do diálogo com } \\
\text { os governos, órgs̃os públicos, filantropos } \\
\text { e comunidades afetadas". }\end{array}$ & $\begin{array}{l}\text { Diálogo entre } \\
\text { arquiteto e } \\
\text { instituições. }\end{array}$ \\
\hline 2015 & ALEMANHA & $\begin{array}{l}\text { "caminhos que se abrirgm graças } \\
\text { às suas pesquisas e descobertas. Suas } \\
\text { contribuições no campo da arquiteturg } \\
\text { não sắo spenas inteligentes e } \\
\text { talentosas. são também generosas. Por } \\
\text { suas ideias visionárias, sua crença em } \\
\text { compartilhar livremente conhecimento e } \\
\text { invenções". }\end{array}$ & $\begin{array}{l}\text { Pesquisas e } \\
\text { descobertas } \\
\text { compartilhadas. }\end{array}$ \\
\hline 2016 & CHILE & $\begin{array}{l}\text { "profundo conhecimento tanto da } \\
\text { arquitetura como da sociedade civil, algo } \\
\text { que se reflete em seus escritos, seu } \\
\text { ativismo e seus projetos. O papel do } \\
\text { arquiteto está agora sendo desafiado a } \\
\text { servir a necessidades sociais e } \\
\text { humanitárias maiores". }\end{array}$ & $\begin{array}{l}\text { Ativismo da } \\
\text { arquitetura em favor } \\
\text { das necessidades } \\
\text { sociais e } \\
\text { humanitárias. }\end{array}$ \\
\hline
\end{tabular}

Tabela 1 • Esquematização visual do Prêmio Pritzker - período 2006 - 2016 Fonte: Autores, 2016. 
Apesar da incidência mais significativa de europeus na premiação, que remete ao hábito do monopólio europeu sobre o desenvolvimento das Artes - inclui-se aqui a arquitetura -, suas técnicas e sua fixação de um molde para os demais países, isso não se manifesta na distribuição nação versus anos do Prêmio Pritzker.

Em 2007/2008/2009 foram laureados arquitetos europeus e em 2012/2013/2014 foram laureados arquitetos asiáticos.

Como o discurso requer do destinatário uma bagagem cultural para melhor entendimento do enunciado e de seu contexto histórico espacial, cabe aqui relembrar que no ano de 2007, a Europa foi marcada por uma grande crise mundial dos últimos 80 anos. A crise financeira mundial atingiu os orçamentos nacionais na zona euro. A recessão de 2009 reduziu, de forma considerável, as receitas públicas e representou um forte peso na segurança social. Entre 2007 e 2010, a dívida pública na zona euro aumentou de $65 \%$ para $85 \%$ do PIB, segundo o Balanço de Resposta Política da U.E ${ }^{14}$.

Ao recorrer à Tabela 1, no período em questão (2007-2009), o ethos construído no discurso do júri, apresentado pela Fundação Hyatt, mostra a transformação social, o debate de normas limitadoras na função e arquitetura de clareza e inspiração.

É possível dizer que esses discursos, montados por meio dos ethos construídos para esses arquitetos premiados, venham a favor de uma Europa arrasada e temerosa diante de uma crise dessa proporção.

Com seu poder de influenciar e engrandecer uma nação pelo seu artista/profissional, dando a ele relevante premiação, o Pritzker parece ter sido dado a europeus com uma astúcia e, ao mesmo tempo, com cuidado social num momento de risco, em que o valor nacional deve ser enaltecido.

Essa valorização de arquitetos, com o objetivo de certa homenagem a países em crise, também aconteceu em 2012/2013/2014, quando o Pritzker premiou três asiáticos consecutivamente.

Nesse período, a Ásia se voltou ao desenvolvimento econômico e sustentável interno, principalmente após o rebaixamento de nota da China pela Agência Fitch, acerca do grau de investimento, mas fez a previsão de reforçar o crescimento da região da Ásia e do Pacífico em 2013/2014, inclusive o Fundo Monetário Internacional também previu um cenário positivo, com o aumento das exportações e consumo interno para 2014, e atualmente, segue se reerguendo.

Outro fato de dimensões internacionais foi o Acidente Nuclear em Fukushima, Japão, em 2011, com derretimento de três reatores nucleares da usina que foram atingidos por um tsunami, ocasionado por um terremoto de magnitude 9,0 na escala Richter. Em 2013, ainda havia muita água radioativa na região, de onde cerca de 300 mil pessoas foram evacuadas, outras 15 mil morreram devido ao terremoto/tsunami.
14. O Balanço de Resposta Política da U. E. foi elaborado pela Fundação Robert Schuman, em 2011, com aval da Representação da Comissão Européia para compreensão e análise da crise que assolou o continente em 2007. 
O ethos construído pelo júri envolveu a China como polo de desenvolvimento de ideais arquitetônicos, produtor de obras que sintetizam as mais variadas linguagens emarquitetura e o diálogo entre arquitetura e instituições, como as de filantropia e órgãos públicos, que coincide com o momento histórico asiático, numa recuperação espacial e valorização de sua força e autonomia.

Em 2016, o Chile, pela primeira vez, entra na lista dos premiados, com um ethos de ativismo para as necessidades sociais e humanitárias. Esse perfil construído se correlaciona ao momento enfrentado no Chile, em 2015, quando um terremoto de magnitude 8,3 na escala Richter atingiu o país, deixando 14 mil desabrigados.

Nesse contexto, Alejandro Aravena se destaca no cenário proposto pela lista de indicados ao Prêmio Pritzker, ao ser arquiteto de habitação de interesse social e considerado inovador na área. Aravena vem propor um ethos de arquiteto engajado às causas sociais e à cidade, não apenas vinculado a projetos individuais, mas que construam espaços socialmente reconhecidos.

Sendo o quarto latino-americano a receber o Prêmio, Aravena, após 10 anos, remete as razões do júri para a então escolha de Mendes da Rocha, último arquiteto brasileiro a receber a honraria, que também atuou em projetos de interesse social, como fator organizador do espaço.

\section{Considerações Finais}

Diante dos resultados analisados, verificou-se que a escolha dos premiados no Pritzker pode estar diretamente relacionada às produções dos elencados e às questões mundiais. Esses dois quesitos, muito bem afinados a uma realidade histórico-social das nações, como reconhecimento de suas crises e desastres, podem ser fatores de escolha de atores, cujos ethos discursados em público, manifestados por um júri especializado, possuam cunho encorajador não só a outros profissionais, mas em seu país. Assim, para entender os sentidos subentendidos em um texto, é preciso que o enunciador e o destinatário tenham um conhecimento partilhado que thes permita inferirem os significados.

\section{Referências}

AMOSSY, R. Da noção retórica de ethos à análise do discurso. In: (Org.). In: Imagens de si no discurso: a construção do ethos. São Paulo: Contexto, 2005.

FIORINDO, Priscila. Ethos: um percurso da retórica à análise do discurso. In: Revista Pandora Brasil No 47, Out. 2012. Disponível em: <http://revistapandorabrasil.com/revista_pandora/ ethos/priscila.pdf>. Acesso em 17 mar. 2017. 
HEINE, Palmira Bahia. Considerações sobre a cena enunciativa: a construção do ethos nos blogs. In: Linguagem em (Dis)curso, v. 8, n. 1, p. 149-174, jan-abr 2008. Disponível em: <http://www.scielo.br/pdf/ld/v8n1/07.pdf>. Acesso em 17 jan. 2016.

MAINGUENEAU, D. Ethos, cenografia, incorporação. In: AMOSSY, Ruth (Org). Imagens de si no discurso: a construção do ethos. São Paulo: Contexto, 2005.

MAINGUENEAU, D. A propósito do ethos. In: MOTTA, Ana Raquel; SALGADO, Luciana. Ethos discursivo. São Paulo. Editora Contexto, 2008.

PRITZKER. Alejandro Aravena 2016 Laureate. Disponível em: <http://www.pritzkerprize .com/laureates/2016>. Acesso em 15 fev. 2016.

Recebido em 19/04/2016

Aprovado em 02/03/2017 
Cadernos de Arquitetura e Urbanismo, v.23, n.33, 2" sem. 2016 